The i mpact of Ge codopi ng on grown- i $\mathrm{n} \mathrm{O}$ preci pi tat es i n Ga- doped Czochral ski-si I i con

\begin{tabular}{|l|l|}
\hline 著者 & $\begin{array}{l}\text { Ar i vanandhan Mikannan, Got oh Rai ra, Fuj i war a } \\
\text { Kozo, Ozawa Tet suo, Hayakawa Yasuhi ro, Uda } \\
\text { Sat oshi }\end{array}$ \\
\hline $\begin{array}{l}\text { j our nal or } \\
\text { publ i cat i on t i tl e }\end{array}$ & Journal of Cryst al Grouth \\
\hline vol une & 321 \\
\hline number & 1 \\
\hline page range & $24-28$ \\
\hline year & $2011-$ O4 15 \\
\hline 出版者 & El sevi er \\
\hline 権利 & $\begin{array}{l}\text { Copyr i ght ( C) 2011 El sevi er B. V. Al I ri ght s } \\
\text { reser ved. }\end{array}$ \\
\hline URL & ht t p: //hdl . handl e. net /10297/5646 \\
\hline
\end{tabular}




\title{
The impact of Ge codoping on grown-in O precipitates in Ga-doped Czochralski-silicon
}

\author{
Mukannan Arivanandhan ${ }^{\mathrm{a}^{*}}$, Raira Gotoh ${ }^{\mathrm{b}}$, Kozo Fujiwara ${ }^{\mathrm{b}}$, Tetsuo Ozawa ${ }^{\mathrm{c}}$, Yasuhiro Hayakawa ${ }^{\mathrm{a}}$, \\ Satoshi $\mathrm{Uda}^{\mathrm{b}}$ \\ ${ }^{a}$ Research Institute of Electronics, Shizuoka University, Johoku 3-5-1, Naka-Ku, Hamamatsu, \\ Shizuoka 432-8011, Japan \\ ${ }^{\mathrm{b}}$ Institute for Materials Research, Tohoku University, 2-1-1 Katahira, Aoba-ku, \\ Sendai 980-8577, Japan
}

${ }^{c}$ Department of Electrical Engineering, Shizuoka Institute of Science and Technology, Fukuroi, Shizuoka 437-8555

\begin{abstract}
:
The intensity of the infrared absorption band at $1107 \mathrm{~cm}^{-1}$, related to interstitial oxygen $\left(\mathrm{O}_{\mathrm{i}}\right)$ concentration, decreased as the Ge concentration increased in $\mathrm{Ga}$ and $\mathrm{Ge}$ codoped $\mathrm{CZ}-\mathrm{Si}$ crystals. In contrast, the number of precipitates observed on the etched surfaces of CZ-Si wafers increased as the Ge concentration increased. From an energy dispersive X-ray (EDX) analysis, O was observed to be one of the major components of the precipitates. Moreover, Ge was found as one of the components in the precipitate observed on the heavily Ge $\left(>1 \times 10^{18} \mathrm{~cm}^{-3}\right)$ codoped CZ-Si wafers. These results suggest that the grown-in $\mathrm{O}$ precipitates increase as the $\mathrm{O}_{\mathrm{i}}$ concentration decreases when the Ge concentration increases in the Si crystal. The Ge-vacancy (V) complex in the Si lattice probably acted as a heterogeneous nucleation center and may enhanced the grown-in $\mathrm{O}$ precipitates thereby reducing the dissolved $\mathrm{O}_{\mathrm{i}}$ concentration in the $\mathrm{Si}$ lattice.
\end{abstract}

Keywords: A2. Czochralski method; B2. Semiconductor Silicon; A1. Codoping; A1. Point Defects

PACS: $81.10 . \mathrm{Fq}, 61.72 . \mathrm{sh}, 71.55 . \mathrm{Ak}$ 
*Corresponding Author: Mukannan Arivanandhan

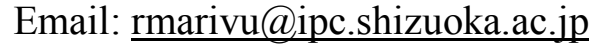

Phone: +81534781338

Fax: $\quad+81534781338$

\section{Introduction:}

Currently, the world's industrial production of solar cells is mainly based on boron (B)doped crystalline silicon (c-Si) which includes single crystalline and multicrystalline (mc) silicon. Generally, solar cell elements using a single-crystal $\mathrm{Si}$ substrate have higher conversion efficiencies than that of mc-Si due to their structural perfections. The single crystal Si substrate material is produced by the Czochralski method using high-purity poly Si. However, the lightinduced lifetime degradation (LID) in B-doped Czochralski-grown silicon (CZ-Si) - due to the formation of B-oxygen complexes with high recombination activity - limits the minority carrier lifetime (MCL) thereby the efficiency of solar cells [1-3]. In contrast, gallium (Ga)-doped CZ-Si was recently identified as a promising substrate material for solar cells since it shows high MCL with no LID effect [3]. Although the Ga-doped CZ-Si shows a high MCL, different types of grown-in micro-defects (GMDs), such as A, B, D, and I type defects may exist in dislocationfree crystals [4], and limit the MCL by acting as recombination centers [5]. Therefore, to further improve the MCL of Ga-doped CZ-Si, thereby the conversion efficiency of the solar cell, it is essential to understand the GMD formation mechanism in CZ-Si and its effects on MCL as well.

In our previous work, we observed a high MCL in Ga-doped CZ-Si by Ge codoping with no LID effect [6,7]. Moreover, we observed that the flow pattern defect (FPD) density was reduced as the Ge concentration increased in the Ga and Ge codoped CZ-Si. The experimental 
results were consistently explained by a defect suppressing model based on a Ge-vacancy (V) defect complex, which enhanced the $\mathrm{O}$ precipitates by acting as a heterogeneous nucleation center [7]. Watkins $[8,9]$ observed a similar substitutionaly placed Ge and vacancy $\left(\mathrm{Ge}_{\mathrm{s}}-\mathrm{V}\right)$ defect complex in Ge containing Si by electron paramagnetic resonance (EPR) studies. Moreover, similar proposals were reported in the literature [10-13] based on infrared absorption and defect studies. In addition, recent computation work by Chen et al [14] highly supports this proposal. In contrast, Chroneos et al [15] reported that the contribution of Ge to the stability of the $\mathrm{GeV}_{\mathrm{n}}\left(\mathrm{V}_{\mathrm{n}}\right.$ is the vacancy clusters with more than two vacancies) clusters is relatively small due to small difference $(0.35 \mathrm{eV})$ between the binding energies of $\mathrm{GeV}_{\mathrm{n}}$ and $\mathrm{V}_{\mathrm{n}}$ clusters and hence Ge does not act as a site that traps a significant proportion of $\mathrm{V}$, contradicting the proposal by Chen et al [14]. Nevertheless, further investigation is needed on experimental as well as theoretical aspects to clarify the effect of $\mathrm{Ge}$ on the formation of $\mathrm{Ge}-\mathrm{V}$ defect complex and $\mathrm{O}$ precipitates in $\mathrm{CZ}-\mathrm{Si}$. In the present report, the interstitial oxygen $\left(\mathrm{O}_{\mathrm{i}}\right)$ concentrations in the $\mathrm{Ga}$ and $\mathrm{Ge}$ codoped $\mathrm{CZ}-\mathrm{Si}$ wafers were measured by means of Fourier transform infrared (FTIR) spectroscopy. The chemical composition of the grown-in $\mathrm{O}$ precipitates on the etched surfaces of the $\mathrm{Ga}$ and $\mathrm{Ge}$ codoped CZ-Si wafers were analyzed by energy dispersive X-ray (EDX) spectroscopy. The results support our proposed model for the defect suppressing mechanism in Ga and Ge codoped CZ-Si crystals [7].

\section{Experimental procedure:}

\subsection{Crystal growth:}

A series of $\mathrm{Ga}$ and Ge codoped $<100>\mathrm{Si}$ single crystals were grown by the Czochralski method with varying $\mathrm{Ge}$ concentration at fixed $\mathrm{Ga}\left(1.5 \times 10^{16} \mathrm{~cm}^{-3}\right)$ concentration. The concentration of Ge in the crystals varied from $1 \times 10^{17}$ to $1 \times 10^{20} \mathrm{~cm}^{-3}$. The growth parameters, 
such as the crystal rotation rate $(\sim 20 \mathrm{rpm})$, crucible rotation rate $(\sim-10 \mathrm{rpm})$, growth rate $(0.70$ $\mathrm{mm} / \mathrm{min}$ during the growth of the crystal body), and crystal diameter (about $70 \mathrm{~mm}$ ) were controlled for all the experiments. Sliced Si wafers (corresponding to $30 \%$ of the solidified fraction) from the grown ingots with different concentrations of $\mathrm{Ge}\left(1 \times 10^{17} \mathrm{~cm}^{-3}\right.$ to $1 \times 10^{20} \mathrm{~cm}^{-}$ ${ }^{3}$ ) were chosen (see Table 1) for the present investigation. The wafers were chemically mirror finished using a mixed acid solution of $\mathrm{HNO}_{3}$ and $\mathrm{HF}$.

\subsection{FTIR Investigations:}

The concentrations of dissolved $\mathrm{O}_{\mathrm{i}}$ in the grown $\mathrm{Ga}$ and Ge codoped CZ-Si wafers (Table 1) were measured by FTIR using a JEOL WIN SPEC-50 at room temperature in atmospheric air. The resolution and number of accumulation of the spectrum were set to $4 \mathrm{~cm}^{-1}$ and 32 times, respectively. The background of the spectrum was calibrated using a sample-free spectrum. Interstitially dissolved $\mathrm{O}$ in $\mathrm{Si}$ exhibits an absorption peak at $1107 \mathrm{~cm}^{-1}$ at room temperature [16]. The concentration of dissolved $\mathrm{O}$ was determined from the absorption coefficient of the peak at $1107 \mathrm{~cm}^{-1}$ using the standard calibration factor $3.14 \times 10^{17} \mathrm{~cm}^{-2}$ [17]. Moreover, a broad peak at $1224 \mathrm{~cm}^{-1}$ can be observed in the spectrum which is related to $\mathrm{SiO}_{2}$ precipitates. This peak can be explained by the excitation of the longitudinal optical (LO) phonon mode of $\mathrm{SiO}_{2}$. The $\mathrm{LO}$ mode is normally infrared inactive for bulk $\mathrm{SiO}_{2}$ but can become active for particles that are small enough to become electrically polarized. Hu's theoretical calculations show that the $1224 \mathrm{~cm}^{-1}$ band arises from particles that are smaller than $\lambda / 2 \pi \mathrm{n}_{\mathrm{m}}$, where $\lambda$ is the wavelength of the incident radiation and $n_{m}$ the refractive index of the embedding matrix and have a plate-like shape [16]. 
2.3 SEM and EDX analysis on the etched CZ-Si wafers:

The wafers were etched using Secco etchant for 10 min to observe the grown in $\mathrm{O}$ precipitates by scanning electron microscopy (SEM) (JOEL JSM-5510). The composition of the grown-in $\mathrm{O}$ precipitates in the etched surfaces of the $\mathrm{Ga}$ and $\mathrm{Ge}$ codoped $\mathrm{CZ}-\mathrm{Si}$ wafers were analyzed by EDX spectroscopy.

\section{Experimental results:}

In Fig. 1(a-e) the FTIR absorption spectra of samples 1-5 (spectra a-e, respectively) are shown in the spectral range from 900 to $1300 \mathrm{~cm}^{-1}$. The spectrum of sample 1 is recorded for CZ-Si wafer doped only with Ga, while those of samples 2-5 (Table 1) show the behavior of the IR spectrum as a function of Ge concentration. All the recorded spectra showed a sharp peak at about $1107 \mathrm{~cm}^{-1}$ related to $\mathrm{O}_{\mathrm{i}}$ concentration. Moreover, no peaks were observed at $1224 \mathrm{~cm}^{-1}$ in all spectra, probably the grown-in O precipitates are IR-inactive due to their large size [16] (which was later confirmed by SEM). Spectrum b of Fig. 1 does not show any remarkable change, being almost the same as spectrum a; it also reveals that a Ge concentration of $1 \times 10^{17}$ $\mathrm{cm}^{-3}$ induces a relatively small number of O precipitates as evidenced in etching studies (Fig. 4). By increasing the Ge concentration to $1 \times 10^{18} \mathrm{~cm}^{-3}$, the $\mathrm{O}_{\mathrm{i}}$-related peak at $1107 \mathrm{~cm}^{-1}$ showed a relatively low intensity (spectrum c in Fig. 1) and the intensity of the peak further decreased as the Ge concentration increased to $1 \times 10^{19} \mathrm{~cm}^{-3}$ (spectrum $\mathrm{d}$ in Fig. 1) and $1 \times 10^{20} \mathrm{~cm}^{-3}$ (spectrum e in Fig 1).

The $\mathrm{O}_{\mathrm{i}}$ concentration converted from the absorption coefficient of the IR absorption peak by a standard conversion factor is plotted in Fig. 2 as a function of Ge concentration. As shown 
in Fig. 2, the $\mathrm{O}_{\mathrm{i}}$ concentration decreased as the Ge concentration increased in the Si crystal from $1 \times 10^{17} \mathrm{~cm}^{-3}$ to $1 \times 10^{20} \mathrm{~cm}^{-3}$. The relatively high $\mathrm{O}_{\mathrm{i}}$ concentration obtained even for a low intensity peak (spectrum d in Fig. 1) at a Ge concentration of $1 \times 10^{19} \mathrm{~cm}^{-3}$ was probably due to the thinness of the particular wafer (refer Table 1). The uncertainty in the converted value of $\mathrm{O}_{\mathrm{i}}$ concentrations (Fig. 2) are possible to occur due to possible errors in the data treatment and the effect of wafer's surface on the peak height is high especially for the thin wafers $(<500 \mu \mathrm{m}$ thick) [18]. However, the effect is same for all the wafers and thus the reduction of $\mathrm{O}_{\mathrm{i}}$ concentration in $\mathrm{Ga}$ and $\mathrm{Ge}$ codoped $\mathrm{CZ}-\mathrm{Si}$ wafers is obvious. These experimental results suggest that the formation of Ge-V complexes (as confirmed by FPD density reduction in our previous report, ref. 7) due to Ge codoping may have forced $\mathrm{O}_{\mathrm{i}}$ to precipitate. As a result, a reasonable decrease in $\mathrm{O}_{\mathrm{i}}$ was observed in $\mathrm{CZ}-\mathrm{Si}$ as a function of Ge concentration. This behavior was also reported in Ge-doped Si [12].

The SEM micrographs of the etched surfaces of samples 1, 3 and 5 (refer to Table 1) are shown in Fig. 3 (a-c). On the etched surface of sample 1 (Fig. 3a), only few grown-in precipitates were observed while on the etched surface of sample 3, grown-in precipitates increased relatively and the average precipitate size was about $\leq 1 \mu \mathrm{m}$. In contrast, the density of grown-in precipitates increased in sample 5 (Fig.3c) with an average size of about $\leq 2 \mu \mathrm{m}$. The variation in density of grown-in precipitates as a function of Ge concentration is shown in Fig. 4. As can be seen from Fig. 4, the density of grown-in precipitates increased as the Ge concentration increased in $\mathrm{Ga}$ and Ge codoped CZ-Si.

Figure $5 \mathrm{a}$ and $5 \mathrm{~b}$ show the EDX spectra recorded for positions A and B marked in Fig 3b. The spectra indicate that the precipitates contain $\mathrm{O}$ and $\mathrm{Si}$, while no O-related peak was 
observed in the EDX spectrum recorded on the precipitate-free surface (Fig. 5b). Figure 6a and $6 \mathrm{~b}$ show the EDX spectra obtained from two locations marked A and B in Fig. 3c. As can be seen from the spectra, two peaks related to $\mathrm{O} \mathrm{K}_{\alpha}$, and $\mathrm{Ge}_{\alpha}$ were observed in the spectrum recorded on the precipitate in addition to the prominent Si peak. However, the spectrum for precipitate-free $\mathrm{Si}$ surface shows only a $\mathrm{Ge} \mathrm{L}_{\alpha}$ peak with a prominent $\mathrm{Si}$ peak. The Ge-related peak in the EDX spectra recorded for the Ga $\left(1.5 \times 10^{16} \mathrm{~cm}^{-3}\right)$ and $\mathrm{Ge}\left(1 \times 10^{18} \mathrm{~cm}^{-3}\right)$ codoped CZ-Si wafer (sample 3; Fig.5a and 5b) was absent, probably due to a low concentration of Ge. According to Hu's [16] theoretical calculations, O precipitates which are larger than about 0.36 $\mu \mathrm{m}\left(\lambda / 2 \pi \mathrm{n}_{\mathrm{m}}\right)$ become infrared inactive; as a result, the $1224 \mathrm{~cm}^{-1}$ peak cannot be observed in infrared absorption spectra. As shown in the SEM images (Fig. 3), the grown-in O precipitates in the present experiments are relatively larger $(\geq 1 \mu \mathrm{m})$ than $0.36 \mu \mathrm{m}$ and hence, the corresponding peak was not observed in the IR spectrum. The experimental results revealed that the $\mathrm{O}_{i}$ concentrations decrease and the grown-in $\mathrm{O}$ precipitates increase as the Ge concentration increases in the Ga and Ge codoped CZ-Si single crystals.

\section{The role of Ge-V defects on $\mathrm{O}$ precipitates}

It is known that the free vacancies in Si diffuse over the lattice with a migration energy of $0.35 \mathrm{eV}$ at high temperature $\left(\mathrm{T}>\mathrm{T}_{\mathrm{vn}}\right.$, where $\mathrm{T}_{\mathrm{vn}}$ is the void nucleation temperature) [19]. Moreover, the free vacancies can diffuse over the Si lattice and form vacancy clusters $\left(\mathrm{V}_{\mathrm{n}}\right.$, where $\mathrm{n}$ is $1,23 \ldots$ ) on subsequent cooling, which can diffuse over a large distance in the Si lattice without dissociation [20]. The activation energy for diffusion of the smallest vacancy cluster, i.e., divacancy, is about $1.25 \mathrm{eV}$, while that for dissociation of a divacancy is higher than $1.6 \mathrm{eV}$ [11]. 
In addition, the growth of faceted voids proceeds by nucleation of a two-dimensional (2D) nucleus and subsequent expansion of the nucleus over the whole facet. The growth of larger voids is rapid since 2D nucleation becomes easy in a larger facet area [21]. The larger voids (which contain up to $4 \times 10^{7}$ vacancies) can differ from the vacancy clusters in their number of vacancies [21]. It is expected that the as grown crystals contain both vacancy clusters and voids. Moreover, in CZ-Si crystals, the cluster density is in the order of $10^{8} \mathrm{~cm}^{-3}$, which is four to five orders smaller than FZ-Si crystals, since vacancies are consumed mostly by voids. In this sense, when $\mathrm{T}<\mathrm{T}_{\mathrm{vn}}$, the vacancy clusters in Ge-free CZ- Si crystals are likely to interact with the dissolved $\mathrm{O}_{\mathrm{i}}$ and form $\mathrm{V}-\mathrm{O}$ and/or $\mathrm{V}_{2}-\mathrm{O}$ related complexes. These defects act as $\mathrm{O}$ precipitation nuclei and are grown as $\mathrm{O}$ precipitates on subsequent cooling $\left(\mathrm{T}<<\mathrm{T}_{\mathrm{vn}}\right)$. This is a possible reason for the small number of grown-in precipitates and large number of FPD defects related to void defects (evidences for FPDs are presented in ref. 7 and 22) observed on sample 1 (Fig. 3a).

In the presence of substitutionally codoped Ge, the fast diffusing divacancies and/or other vacancy clusters can interact with Ge atoms $\left(T>T_{\mathrm{vn}}\right)$ in the course of post-growth cooling and form a Ge- $\mathrm{V}_{\mathrm{n}}$ defect complex. The formation of such a complex is more feasible when the ingot temperature $T$ is higher than $T_{v n}$, since the binding energy of the Ge- $V_{n}$ defect complex is higher - up to $0.35 \mathrm{eV}$ - compared to $\mathrm{V}_{\mathrm{n}}$ clusters [15] and the activation energy for vacancy diffusion is then low - about $0.36 \mathrm{eV}^{20}$. Furthermore, there is infrared absorption evidence for the interaction of divacancies $\left(\mathrm{V}_{2}\right)$ with impurities $[11,23]$. As a result of the $G e-\mathrm{V}_{\mathrm{n}}$ complex formation, the free vacancy concentration reasonably reduced and thus the void nucleation were possibly suppressed. On subsequent cooling of the ingots $\left(\mathrm{T}<<\mathrm{T}_{\mathrm{vn}}\right)$, the supersaturation of $\mathrm{O}_{\mathrm{i}}$ in $\mathrm{Si}$ becomes larger and the $\mathrm{O}_{\mathrm{i}}$ precipitates may be grown using $\mathrm{Ge}-\mathrm{V}_{\mathrm{n}}$ as a nucleation site. Furthermore, when the Ge concentration increases, the possibility of a Ge- $\mathrm{V}_{\mathrm{n}}$ complex formation 
is relatively increased which results in large number of precipitates on the heavily Ge codoped CZ-Si wafers (Fig. 3c). Subsequently, the experimental results suggest that the reduction of $\mathrm{O}_{\mathrm{i}}$ in $\mathrm{Ga}$ and $\mathrm{Ge}$ codoped $\mathrm{CZ}-\mathrm{Si}$ is probably due to $\mathrm{O}$ precipitation growth using $\mathrm{Ge}-\mathrm{V}$ defect complex as nucleation sites. Moreover, it is worthwhile to mention that the grown-in precipitates would have less ability to limit carrier lifetime in the presence of D-type void defects as they are smaller than void defects [4].

\section{Conclusion:}

We have experimentally shown that the dissolved $\mathrm{O}_{\mathrm{i}}$ concentration decreased and the number of grown-in $\mathrm{O}$ precipitates increased as the $\mathrm{Ge}$ concentration increased in $\mathrm{Ga}$ and $\mathrm{Ge}$ codoped CZ-Si crystals. From the EDX analysis, it was observed that $\mathrm{O}$ was one of the major components of the grown-in precipitates. Moreover, Ge was found to be one of the components in the precipitate observed on heavily Ge $\left(>1 \times 10^{18} \mathrm{~cm}^{-3}\right)$ codoped CZ-Si wafers. The results suggested that the grown-in $\mathrm{O}$ precipitates increased with a decrease in $\mathrm{O}_{\mathrm{i}}$ concentration as the Ge concentration increased in the Si crystal. From the results one can infer that the $G e-V_{n}$ defect complex may acted as a favorable heterogeneous nucleation center for the $\mathrm{O}$ precipitates especially in the heavily Ge codoped CZ-Si wafers thereby enhanced the density of grown-in precipitate during post growth cooling of the ingot.

\section{Acknowledgement:}

This work was financially supported by a Grant-in-Aid for Young scientist B (no. 22760005) from the Ministry of Education, Culture, Sports, Science and Technology of Japan. 
References:

[1] S.W. Glunz, S. Rein, W. Warta, J. Knobloch, and W. Wettling, Prtoceedings of the $2^{\text {nd }}$ world conference on Photovoltaic Energy Conversion, Vienna, Austria (European Commission, Ispra, Italy, 1998), P. 1343.

[2] J. Schmidt and A. Cuevas, J. Appl. Phys. 86, (1999) 3175.

[3] S.W. Glunz, S. Rein, J.Y. Lee, and W. Warta, J. Appl. Phys. 90, (2001) 2397.

[4] A.J.R. De Kock, Appl. Phys. Lett., 16, (1970) 100.

[5] T. H. Wang, T. F. Ciszek and T. Schulier, Solar cells, 24, (1988) 135.

[6] M. Arivanandhan, R. Gotoh, K. Fujiwara, S. Uda, Appl. Phys. Lett. 94, (2009) 072102.

[7] M. Arivanandhan, R. Gotoh, K. Fujiwara, S. Uda, J. Appl. Phys. 106, (2009) 013721.

[8] G. D Watkins, IEEE Trans. Nuclear Science 16, (1969) 13.

[9] G. D. Watkins, Chin. J. Phys., 15, (1977) 92.

[10] A. Brelot and J. Charlemagne, Radiat. Eff. and Def. Sol., 9, (1971) 65.

[11] Yu. V. Pomozov, M. G. Sosnin, L. I. Khirunenko, N. V. Abrosimov, and W. Schroder, Semiconductors, 35, (2001) 890 .

[12] D. Yang, X. Yu, X. Ma, J. Xu, L. Li and D. Que, J. Cryst. Growth 243, (2002) 371.

[13] J. Chen, D. Yang, X. Ma, W. Wang, Y. Zeng, and D. Que, J. Appl. Phys., 101, (2007) 113512.

[14] J. Chen, T. Wu, X. Ma, L. Wang, and D. Yang, J. Appl. Phys., 103, (2009) 123519.

[15] A. Chroneos, R. W. Grimes, and H. Bracht, J. Appl. Phys., 105, (2009) 016102,.

[16] S. M. Hu, J. Appl. Phys., 51, (1980) 5945.

[17] H. J. Moller, L. Long, M. Werner, D. Yang, Phys. Status Solidi a, 171, (1999) 175. 
[18] Y. Itoh, T. Nozaki, Jpn. J. Appl. Phys. 24 (1985) 279.

[19] G. D. Watkins, J. Phys. Soc. Japan 18, (1963) 22.

[20] G. D. Watkins and J. W. Corbett, Phys. Rev. 138, (1965) A543.

[21] V. V. Voronkov, and R. Falster, J. Cryst. Growth 204, (1999) 462.

[22] R. Gotoh, M. Arivanandhan, K. Fujiwara, S. Uda, J. Cryst. Growth (in press) 2010.

[23] V P Markevich, A. R. Peaker, J. Coutinho, R. Jones, V. J. B. Torres, S. Oberg, P. R.

Briddon, L. I. Murin, L. Dobaczewski and N. V. Abrosimov, Phys. Rev. B 69, (2004) 125218. 
Table 1: Characteristics of the six CZ-Si wafers studied

\begin{tabular}{|c|c|c|c|}
\hline $\begin{array}{c}\text { Sample } \\
\text { number }\end{array}$ & $\begin{array}{c}\text { Ga concentration } \\
\left(\mathrm{cm}^{-3}\right)\end{array}$ & $\begin{array}{c}\text { Ge concentration } \\
\left(\mathrm{cm}^{-3}\right)\end{array}$ & $\begin{array}{c}\text { Thickness of the wafers } \\
(\mu \mathrm{m})\end{array}$ \\
\hline 1 & $1.5 \times 10^{16}$ & 0 & 450 \\
2 & $1.5 \times 10^{16}$ & $1 \times 10^{17}$ & 450 \\
3 & $1.5 \times 10^{16}$ & $1 \times 10^{18}$ & 450 \\
4 & $1.5 \times 10^{16}$ & $1 \times 10^{19}$ & 350 \\
5 & $1.5 \times 10^{16}$ & $1 \times 10^{20}$ & 450 \\
\hline
\end{tabular}


Figure captions:

Figure 1: Infrared absorption spectra of samples 1-5 (curves a-e). The spectra have been shifted for clarity.

Figure 2: $\mathrm{O}_{\mathrm{i}}$ concentration as a function of Ge concentration in the $\mathrm{Ga}$ and $\mathrm{Ge}$ codoped CZ-Si crystals.

Figure 3: SEM images of the etched surfaces of Ga and Ge codoped CZ-Si crystals. (a). Ge-free CZ-Si, (b). Ge $\left(1 \times 10^{18} \mathrm{~cm}^{-3}\right)$ codoped CZ-Si, (c). Ge $\left(1 \times 10^{20} \mathrm{~cm}^{-3}\right)$ codoped CZ-Si.

Figure 4: Density of grown-in O precipitates as a function of Ge concentration.

Figure 5: (a) EDX spectrum of the grown-in precipitate (position A marked in Fig. 3b).; (b) EDX spectrum of the precipitate-free surface (position B marked in Fig. 3b).

Figure 6: (a) EDX spectrum of the grown-in precipitate (position A marked in Fig. 3c); (b) EDX spectrum of the precipitate-free surface (position B marked in Fig. 3c). 
Fig. 1

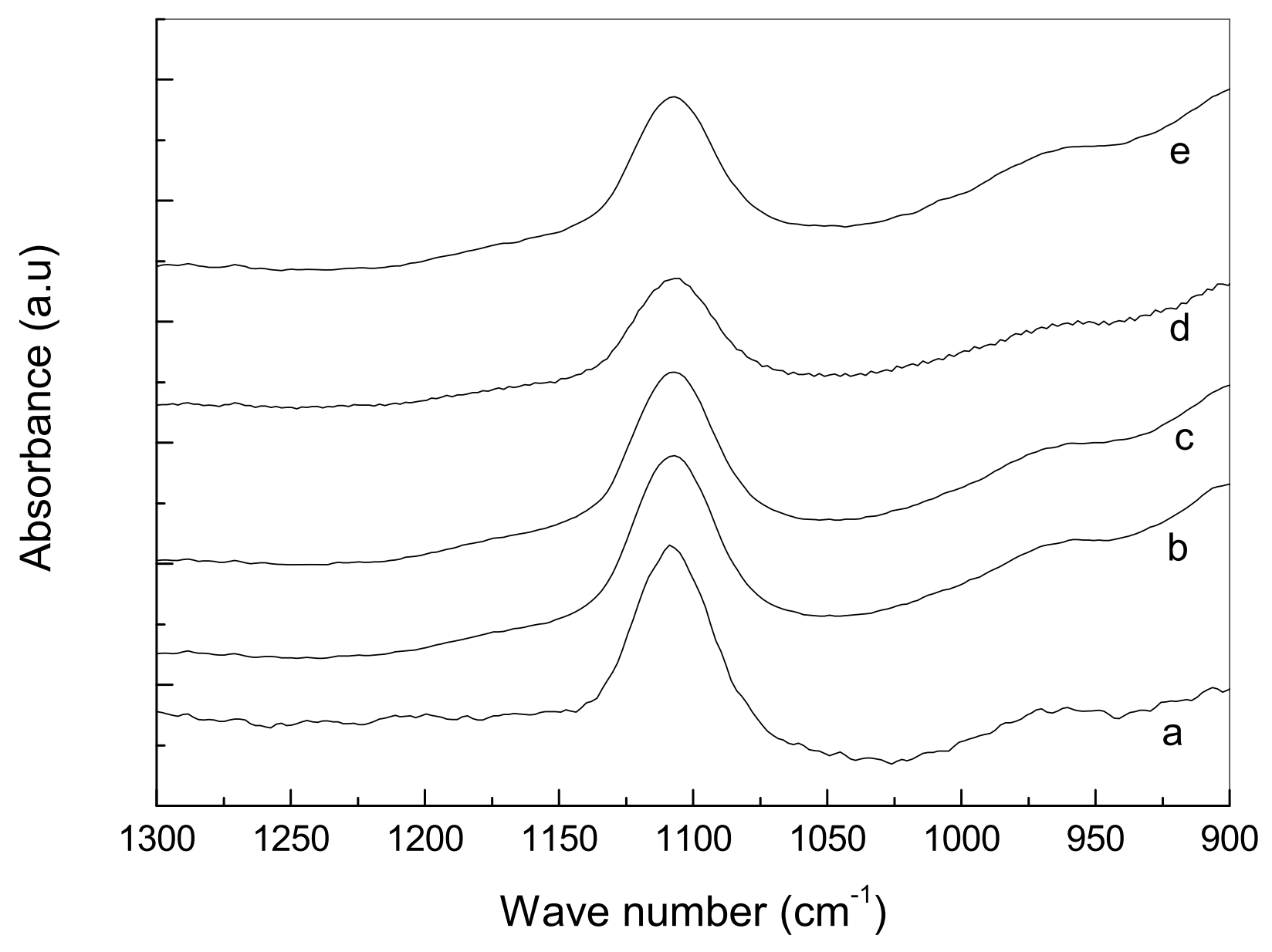


Fig. 2

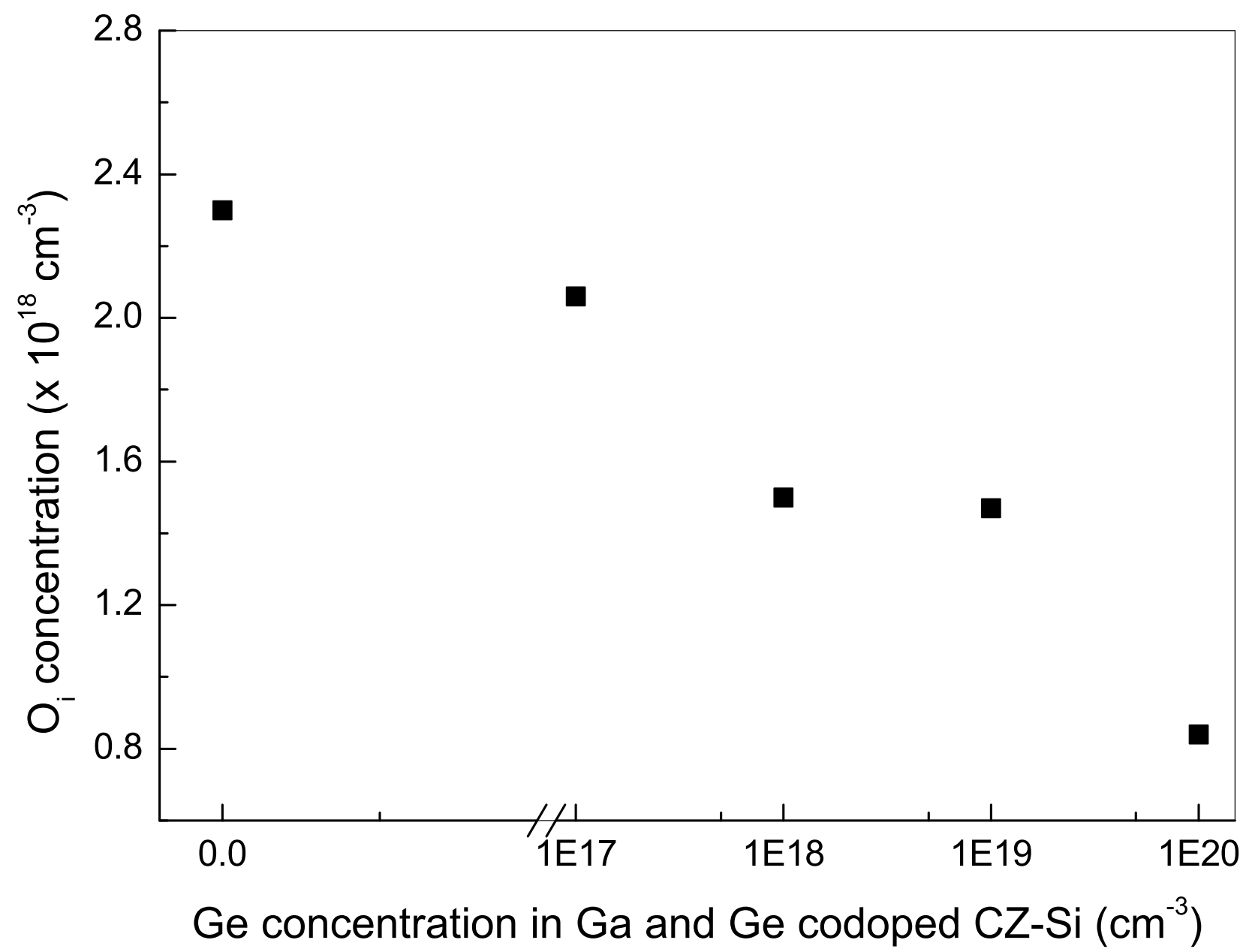


Fig. 3

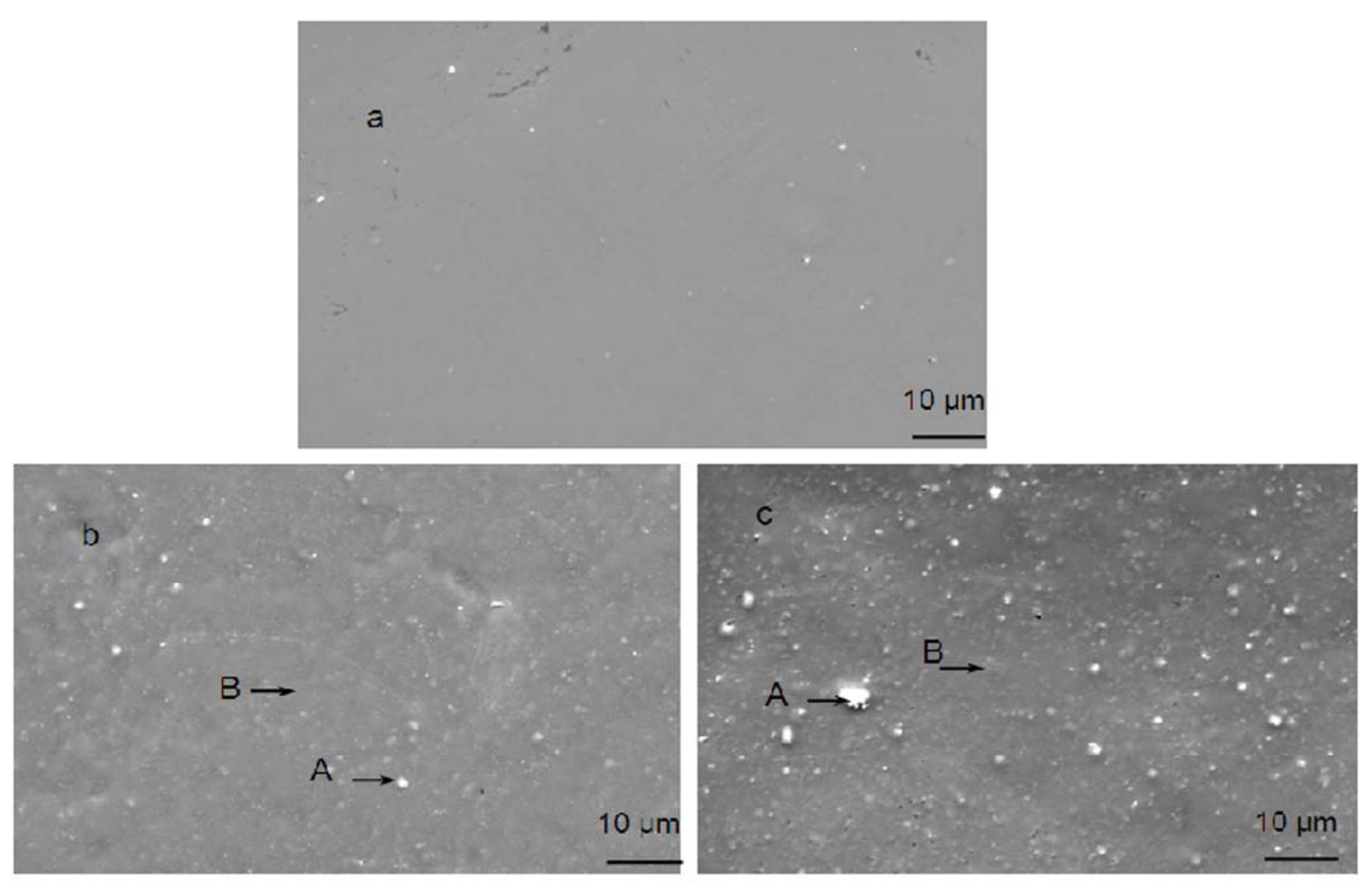


Fig. 4

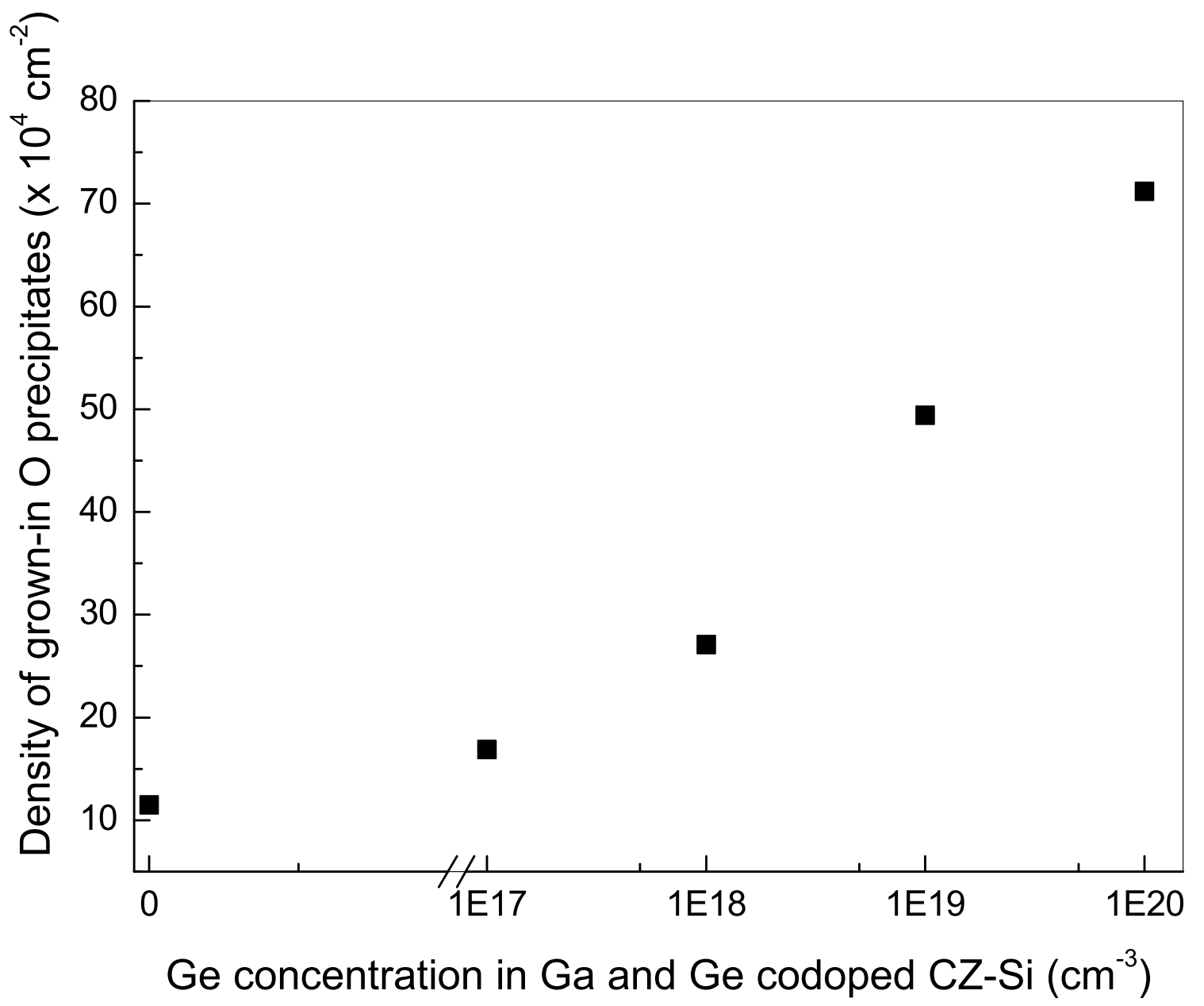


Fig. 5

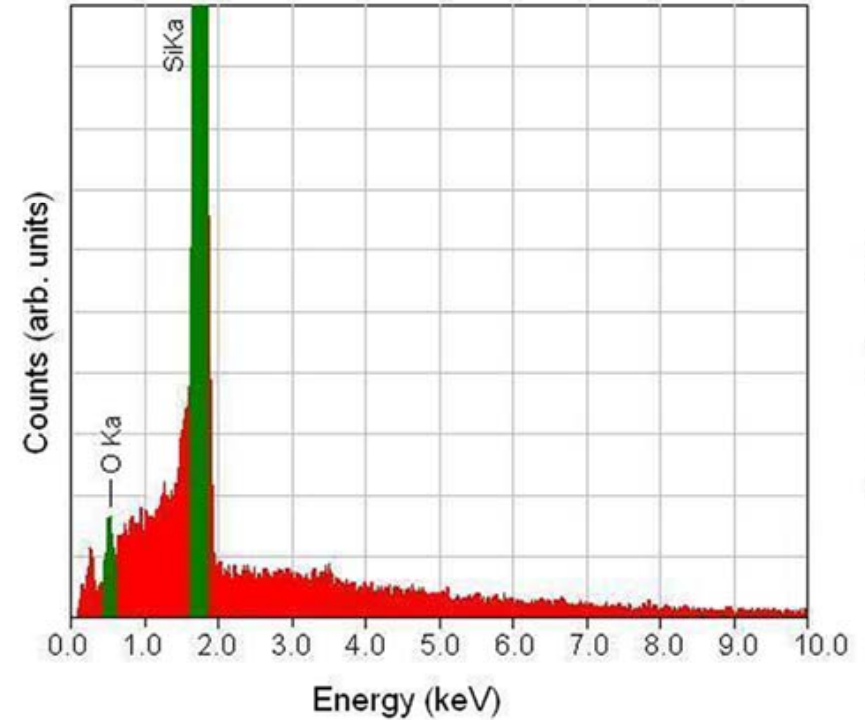

a

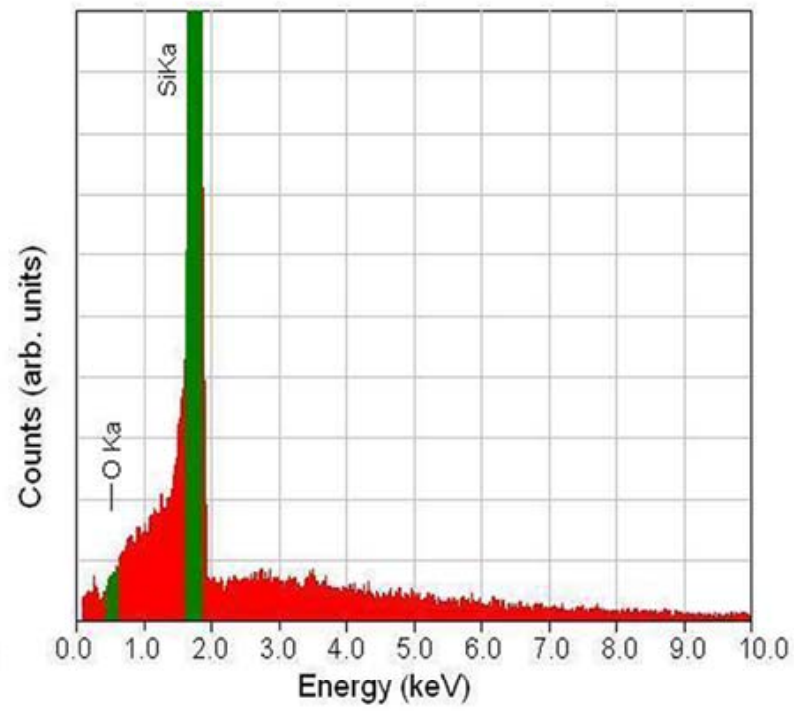

b 
Fig. 6

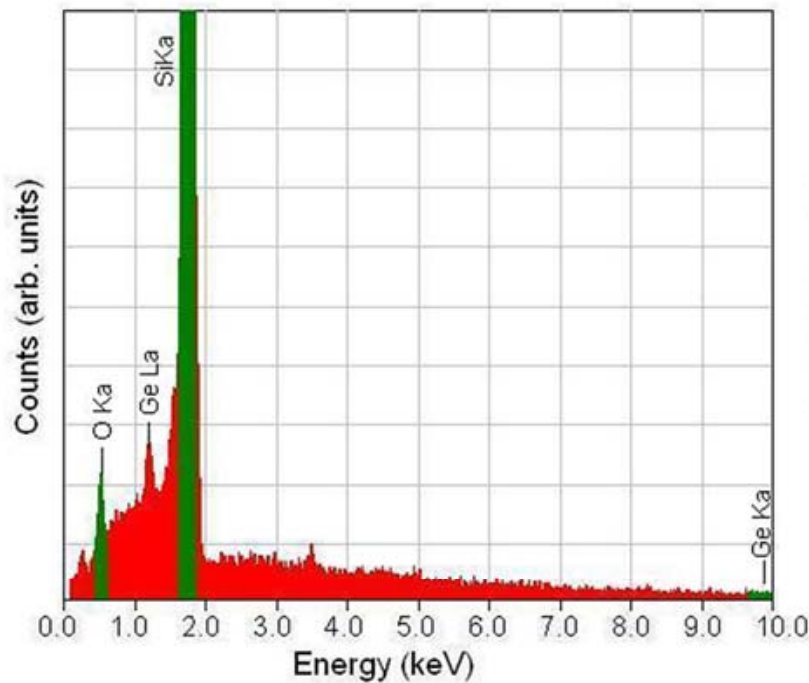

a

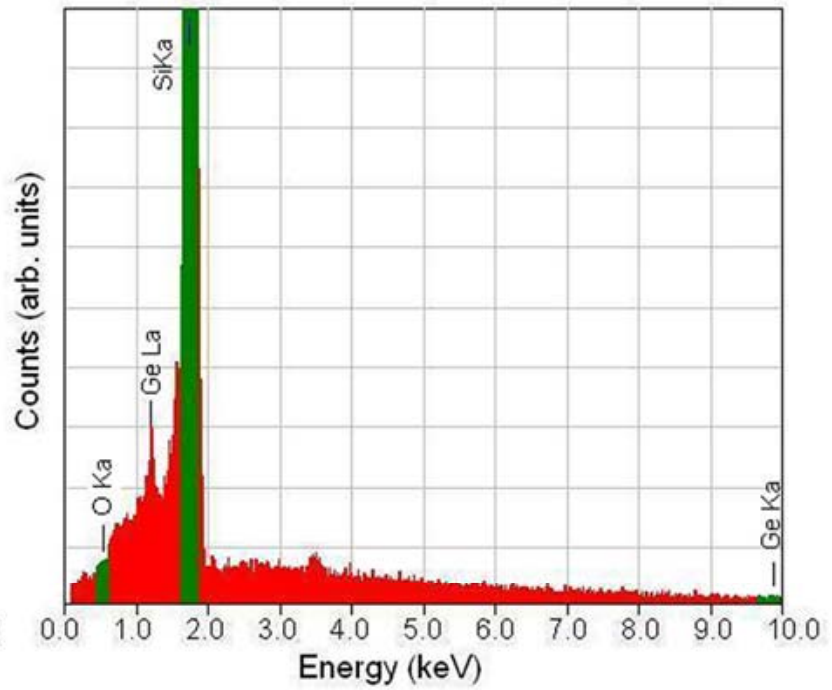

b 